\title{
AC 2011-875: LESSONS MISSED: WHERE IS THE LEARNING ABOUT TEACHING IN STUDY ABROAD?
}

\section{David Jan Cowan, Indiana University Purdue University, Indianapolis}

Dr. Cowan is the Director of and an Associate Professor in the Architectural Technology Program within the Purdue School of Engineering and Technology at Indiana University Purdue University Indianapolis (IUPUI). He teaches courses in residential and commercial construction, facilities management, building systems and interior design. His research interests lie in the areas of disaster reconstruction, BIM (Building Information Modeling), visualization, sustainable community and construction practices, international service learning and energy simulation. He is a graduate architect (Calgary, Canada) with degrees in art education, visual arts and sustainable architecture (LEED AP). He is the co-founder of Global Design Students which is an international education collaborative that addresses building design in various locales around the world, most recently in Thailand, Hawaii, Indonesia and New Orleans. Dr. Cowan is also the Director of Service Learning Initiatives in the School of Engineering and Technology at IUPUI. He has practiced as an architectural designer in the private sector and has taught in post secondary institutions in several countries. He is the Program Chair of the Architectural Engineering Division of ASEE.

\section{J. Craig Greene, College of the North Atlantic \\ Modibo Boubacar Traore, IUPUI-Purdue School of Engineering and Technology \\ Wanda L Worley, Indiana University Purdue University, Indianapolis}

Dr. Worley is associate chair of the Department of Design and Communication Technology and director of the Technical Communication Program. Her research interests are in the scholarship of teaching and learning and in online teaching and learning.

\section{Dr. Tarawut Boonlua, Mahasarakham University}




\section{Lessons Missed: Where is the Learning about Teaching in Study Abroad?}

Introduction

Study abroad programs are increasingly gaining popularity in the United States and it has been noted $^{1}$ that

...in 2007/08, about 262,000 American students studied abroad in foreign countries. This is an $8.5 \%$ increase in participants from the previous year. Ten years ago, approximately 114,000 took part in such programs abroad. That represents a nearly $130 \%$ increase in study abroad participation over the last decade.

It is not unusual to see architectural and architectural engineering programs in this mix as it could be argued that one of the compelling reasons for study abroad, irrespective of the discipline, is the interest in seeing foreign architecture first hand. This does not seem out of place with what we are charged to do as architectural educators.

Few of these programs, however, focus upon the teaching of architecture in other cultures and spend even less time assessing how the architectural instructors of the host country teach their students and how their practices may differ from those in the United States. Furthermore, as Engle and Engle noted, it is becoming more and more difficult to acquire experiences that are truly different and rich: While earlier study abroad offered a marked, desired break with the familiar, the pervasive effects of global economic, social and technological homogenization have made the potentially rich and rewarding encounter with difference less easily acceptable ${ }^{2}$.

How often do we seek out and easily find American experiences, food and culture in our host countries? How far from home do we really feel? How different is the country and the architecture we are visiting and viewing?

This paper explores the lessons learned, and often missed, with respect to witnessing teaching in a foreign country. It examines, describes, and reflects upon the value of experiential education, community engagement, in-classroom techniques, as well as unique S.E. Asian teaching practices and celebrations that forge initial bonds between students and their teachers. These teaching lessons learned through study abroad are compared to the architectural engineering education practices in North America. This paper examines methods for developing respect for teachers, for engaging in the architectural creative process and for paying respect to Asian culture and spiritual beliefs. It highlights the notion that we, as architectural educators, could do more to set the stage for our daily interchanges with our students.

As noted above, this paper intends to move beyond the wealth of architecture that these students were exposed to and delve into the uniqueness of the educational experience both from student and practitioner viewpoints. This paper covers a broad expanse of pedagogy and brings to the discussion an examination of immersive, experiential education that is project-based. It also taps into service learning and the manner in which the American students and faculty gained knowledge from the village elders and the Thai professors and students. This paper will also discuss experiences both within and outside the classrooms at these institutions that led to a 
greater appreciation and understanding of Thai education. It should also be noted that this discussion will include detailed comments from one of the Thai educators, an educator and architect from Canada as well as a graduate student from the USA.

\section{Literature Context}

Our concern in this paper is the absence of studies that focus on teaching in a study abroad context. Several architectural schools, over the course of many years, have incorporated study abroad into their programs and, quite naturally, have focused on the wealth of new found architectural wonders in foreign lands. However, there are also many architectural schools (e.g., Penn State, Virginia Tech., Harvard) that during their study abroad programs, move beyond mere architectural photo opportunities and become involved in studio orientated projects in local communities. Cornell University, for example, has a new (2010) study abroad experience in Korea that seeks "to gain a better understanding of how architecture operates in international and regional geopolitical conditions" ${ }^{3}$. This is also in keeping with the plethora of articles that speak to these community-based international projects in architectural education (e.g., Crisman ${ }^{4}$, Young-Puh ${ }^{5}$, Bing $^{6}$ ).

Yet there are also other scholars, such as Mazumdar, who have explored architectural education beyond "...simply the imparting of knowledge and skills necessary for practice..." and, instead, have begun looking at what was taught and how it was taught in an international context (India). This has also been explored through a framework of looking at the education as to "...how one goes about seeking, acquiring, and transmitting that knowledge" ${ }^{7}$. However not many authors follow her example, nor seek out a research focus on international design education.

It is also important in this discussion to recognize how the current focus on sustainable and green architectural projects places an even greater emphasis on the importance of cultural awareness. As noted by Brady ${ }^{8}$ : "Sustainable architecture involves many issues... [including] environmental, social, and cultural responsibility and awareness." She goes on to state, "The key to achieving sustainability, whether in architecture, business, or the environment, is the ability to understand the larger context," hence the importance of paying attention to cultural subtleties while on these study abroad programs, many of which are imbedded in the teaching and often lost when the priority is photographing local architectural wonders. As design educators, the viewing and examining of international differences in teaching becomes a wonderful opportunity to cast the mirror upon our own teaching and attempts to get to know our students.

If one looks at the literature in international design education, there are more scholars who are pursuing the study of teaching in international contexts (e.g., Poole ${ }^{9,}$ Desimone, Smith, Baker and Ueno ${ }^{10}$ ). This has logically also spread to the discourse on online teaching (e.g., AmbrandtDahlgren, Larsson and Walters ${ }^{11}$ ). For in many instances online teaching is international when students are coming into virtual classrooms from various corners of the world. It is also important, as several authors note (e.g., Dolby and Rahman ${ }^{12}$ ), that: "Until recently, international education has existed at the margins of educational research. However, in the current context of globalization, international education has moved closer to the center of educational research throughout the world". 
It is therefore necessary to bring this to the forefront of architectural education and use these study abroad experiences to enrich our understanding of good teaching as well as our understanding of good architecture.

As we embed ourselves and our students in these international experiences and community-based design projects, our teaching methods naturally touch upon project-based and experiential learning. These methods have been the standard of architectural education for some time as our design education in North America has always relied heavily upon Bauhaus-like instruction: studio courses, critiques, and hands-on learning. However, as we travel around the world, either virtually or not, there are innumerable lessons to be learned about teaching.

Place all of this discourse within a context of that country's primary belief system and the landscape changes as well. This paper's discussion focuses on Thailand and a country that is primarily Buddhist and naturally the lessons about teaching become tempered with Buddhist philosophy and practices. It is extremely interesting to North Americans to watch this interplay of Buddhist culture within architectural and design education. If one explores these articles that couch this education within design, the number of articles that compare the practices of teaching to North American practices of teaching is lean and, in an architectural context, the literature typically strays to a focus upon how Buddhist principles affect construction or design elements (e.g., Tadanao and Edwards ${ }^{13}$ ).

Most often, as noted by Colless ${ }^{14}$, "Religions are maintained through the activities of their priests, prophets, and preachers, but the religious teacher seems to stand somewhat in the background". How often in North American design education is this true? However the experiences noted in the following discussion indicate that Buddhist principles play a large role in the teaching and education of Thai design students. It was our privilege to be able to view these along with the typical things we learn about architecture in a foreign country.

\section{Physical Context}

The setting for this particular discussion is Thailand and in particular two host universities: Rajamangala University of Technology (RMUTT) and Mahasarakham University (MU). RMUTT is one hour North of Bangkok and the experience noted herein was within the Faculty of Architecture. Students from Indiana University Purdue University Indianapolis (IUPUI) spent one week at this institution observing several schools and programs which culminated at the end of the week in a visit to an architectural class that was in the midst of designing a student center on the edge of the campus' east border. The discussion that follows is centered upon this experience and the interchange between the students and faculty from both cultures.

The IUPUI students also spent one week at Mahasarakham University (MSU) following the visit to RMUTT. MSU is a day drive northeast of RMUTT and lies near the edge of the Laos border. The professors from the Faculty of Architecture, Urban Design and Creative Arts at this institution had developed a workshop that focused upon a neighboring village. The villagers had requested help in re-examining the use and type of bamboo products that would financially benefit their community. Multicultural groups of students were charged with developing new bamboo products for the villagers. Our examination of this experience in this paper will revolve around the various activities that led to the design of several of these new ideas and concepts. It 
will also discuss teacher and student interactions and ceremonies that made this experience memorable and worthy of discussion to a broader audience of educators.

Methodological Framework

Our methodology was participant observation and photographic journaling, as well as informal dialogue with the participants and local educators and students (though there were significant language barriers). Our intent was not to collect this data in a formal way, particularly since we weren't aware from one minute to the next what the upcoming agenda or experience might be. We acted much like visual anthropologists and ethnographers caught up in the excitement of the activity and hence these comments take on personal biases. Within, there is also some repetition to the comments. However these are purposeful and are used to highlight similarities and differences between the narratives from each commentator. The narrators also add information about events as the discussion proceeds, so the reader needs to take into account that additional comments will typically follow that may add to the understanding of the context and the experience. An overview of these discussions follows the comments from the last contributor.

\section{Reflective Comments from a Thai Perspective}

The following edited comments have been generously submitted and approved by our Thai host at Mahasarakham University, Dr. Tarawut Boonlua, Associate Dean of the Faculty of Architecture, Urban Design and Creative Arts. The discussion begins by describing a teacherstudent appreciation ceremony that lasted an entire morning during our visit. The complete student body was present, along with monks, musicians, practitioners, faculty, and administrators. The final part of his discussion makes comments on the differences between Thai and American architectural education systems and how this affects the type of architecture they produce.

He begins:

In Thai Culture there is a tradition between instructors and students that every student strongly respects: the student has to learn knowledge from their instructors and that this has been performed throughout history from the past to the present. Every student must give this respect to their instructors because they are required to learn knowledge from them and they realize that every student must have an instructor to teach the knowledge to them. The ceremony I discuss herein has continually occurred in the beginning of each academic year and allows the students to show their respect to their instructors. This also shows that the instructors have already accepted the students to transfer knowledge to them, hence this ceremony can be a witness to the commitment between them, and we call this Thai sacred ceremony to indoctrinate the art pupils the Wai-Kru Ceremony.

The salutation or greeting from students to instructors occurs by bringing the hands together to the face is the Thai tradition to pay respect between them. It is a stricter tradition with a student who studies arts. The Architecture Program is a combination of courses between sciences and the arts; therefore the architecture student is strongly linked to tradition. Moreover, the salutation from students is not only to their instructors, but they also must strongly respect the senior students. This is the way the architecture student in Thailand normally pays respect. The 
salutation to instructors is also the way to show respect to all arts' devas and artisans, and this is the way to remind one that the service performed is for their instructors who are teaching knowledge taught to everyone in the past to the present. This also indicates that they are ready to learn the knowledge by paying serious attention and by being good, diligent students, the outcome of which is that the students can use the knowledge given them for their profession in the future.

This Thai sacred ceremony to indoctrinate the art pupils is the way to show acceptance of the teaching from the instructors to the students, as well as this is the announcement of the instructor's acceptance into the same group of arts' devas and all artisans before them. Therefore, the ceremony has to invite the holy spirits of arts' devas and all of artisans to be a witness to the students when they participate in the Thai sacred ceremony. This is an extremely important part of the ceremony. After the students have attended the ceremony, they then believe they can learn and practice and pass through the program. Thus this ceremony is typically scheduled at the beginning of every academic year. It should be noted that one part of the ceremony has an instructor holding a student's hand to help teach them how to draw. This is a very important moment in the ceremony as the students must use this knowledge with great care for this knowledge can damage any community and is an important point to consider in their professional ethics. The professors also tie a string to the students' wrists and sometimes neck while wishing them well in their studies. The string becomes a physical memory of the ceremony and should be kept on for several days.

Even though the respect from student to instructor seems less than before (especially in a large city such as Bangkok) this tradition is still very strict in other regions of Thailand. It shows the culture still applies there, and the student really gives attention to the lecture. Therefore it is hard for students to complain to their instructor; however this is changing over time.

The student in America and Western culture does not show as much respect; they usually tell their instructors what their needs are. Consequently, this could show the difference between cultures. Yet it is very difficult to compare the good and benefits between them. Moreover, Thai culture strongly shows the spiritual beliefs; students will make decisions related to the culture and spiritual beliefs before the physical. The architecture is presented within the context of their own culture because they are learning to pay respect to the culture. Thus schools of architecture in Asia normally attempt to conserve the culture and present the tradition such as the Wai-Kru Ceremony every year.

There are many differences in architectural education contexts between North America and Thailand; first of all there are many differences in student participation/involvement. Experience shows that the American or Western student has been encouraged to participate in the classroom on assignments or classroom discussions since they were young. They have also applied this type of participation outside of the classroom so that this idea is not unfamiliar to them.

On the other hand, the student in Asian culture, particularly with the Thai student, since 19701990 it was difficult to gain knowledge about participation in the classroom and their daily life. It is difficult for them to share ideas or their opinions to other participants. They usually have been quiet in the classroom, showing that they are really concentrating on the issue that the instructor is pointing out to them. If they have any idea on any issue, they usually do not directly 
voice it. Therefore, this very often gives the idea to others that they do not feel comfortable to give their ideas. This shows the main different between the two types of students.

Another issue is on the expression of the students' ideas. The American or Western student has been expressing their ideas without any limitation. The outcome of their work often reveals new and creative ideas, without limits; we can consider their work is like moving forward to a new style of architecture. This happens in many of their architectural studios at various project levels; they can express their ideas without any limitations. Conversely the Thai student is usually strictly focused on Thai vernacular architecture and culture. The outcome is usually a design mixed between a new style and the Thai context and consequently they are often considered Thai contemporary. The other issue is that Thai students are always strictly focused on the Buddhist religion and thus express these beliefs, such as Fung-Sui. Hence, this limitation has shown on the style of the Thai architecture student. Culture most always influences their design.

Moreover, the Office of Higher Education Commission in Thailand has just introduced the brand new Thailand Qualification Framework (TQF) in July 2009 and therefore all of the universities in Thailand have to review their curriculum within 2012. A main framework has been added the curriculum framework with five domains in the minimum. The main domain is concerned with moral principles and moral behavior, which is involved with all courses. Every course in architecture also has to have this added; consequently the architecture students have more training in moral principles and moral behavior in their higher education than before. Therefore, this is the other issue that has made the Thai architecture student different from the American and Western student. Moreover, the opportunity of the Thai student to select their elective subject is quite difficult [limited] because their time table is fixed on the main subjects. On the other hand, the American student can choose their elective subjects by themselves, so that shows the freedom they have to design their program. Thus, they will have the knowledge that they really want to have.

In closing it should be noted that it appears that the Wai-Kru ceremony only benefits the students; however it does lead to the setting up of boundaries between the students and their instructors. For example, if a student has a really strong idea the instructor may not accept it. The student will tend to change their idea, following the instructor's comments and critique, even though the instructor's comments are not the correct solution for the project. This indicates that the student cannot express their ideas freely or fully because of the respect they are required to hold for the instructor. Rarely do students and instructors argue as there would be a lack of respect if the student thought that the instructor was incorrect.

On the other hand, the American or Western student can freely discuss/argue the design idea with the instructor. To see this in Thai culture is far away, and because the instructor is always right and the student is always wrong they may not get the best solution for their design.

\section{Reflective Comments from a Foreign Faculty Perspective}

The comments that follow have been submitted by our Canadian colleague, instructor, and architect who was on his first journey to Thailand and these schools. Craig Green, Program 
Coordinator at the College of the North Atlantic, Newfoundland, Canada has entitled his narrative as follows:

An Architectural Instructor Viewpoint on Study Abroad: The Visual vs The Verbal

When confronted with the experience of education in a foreign country, one is faced with the concept of language and culture being either a barrier or a bridge to understanding.

When the ability to verbally communicate effectively is removed one must rely on the other senses to interpret the situation. Tone, inflection, facial expressions and the well-known art of pointing become visual clues to expressing oneself. Cultural differences can, of course, be challenging and quite frankly one of the high points of the travel experience whether for holiday or education.

However the minefield which must be navigated carefully is not so much the ability to be understood but rather the ability to offend. The slightest transgression which would be meaningless at home may in fact provide a death knell to positive cultural interactions abroad. In order to understand the communications of a culture and language you are unfamiliar with, you can rely upon visual clues. With that in mind, there exist three preeminent philosophies of Thai life that one should be cognizant of. In the following I will focus on the ingrained aspects of Thai life that help translate the visual.

One of the first things that strikes you about a group of Thai students assembling for class is their child like demeanor. One is quickly aware of the body language that indicates a reserved glee that, for North Americans, would be more at home in a grade school than at a university. Laughter is a common event and is indicative of the Thai "Sanuk" or sense of fun ${ }^{15}$. Sanuk does not mean that Thais do not take their work seriously; they do, but it is an interactive way of looking at life, of living in the moment and deriving joy from it. I was quite often amazed and happy to see the wonderful sense of humor of the Thai's we encountered along the way and how humorous and boisterous they could indeed be.

Sanuk is also loosely connected to the concept of "saving face." Thais will go to great lengths to avoid confrontation or to cause embarrassment to themselves or others. As a result, the American concept of anger or raising your voice will most likely yield the opposite result. These displays of antagonism will result in the loss of face for the Thai and will not be a constructive solution to the problem.

This brings me back to Sanuk as a methodology to diffuse an awkward situation. A curious smile may develop on the face of your Thai companion. This may be interpreted by westerners as indifference to the situation, but rather it is paramount to the Thai's desire to save face. One must also factor in the desire to be a good host makes it difficult for Thais to point out your transgression, regardless of how egregious they may be.

The final point to be made in this line of the discussion is that of social status, and this is manifested in Thailand by the concepts of Phu Yai (big people) and Phu Noi (little people). Hoftstede $^{16}$ refers to this as "Power Distance." Power distance refers to the perceived level of dominance of one group over another. A society has "high power distance" when it emphasizes 
the gap between junior and superior. If this gap is de-emphasized, then the society has "low power distance" and tends to be less hierarchic. Hofstede suggests that Thai society has high power distance. He also states:

The high Power Distance (PDI) is indicative of a high level of inequality of power and wealth within the society. This condition is not necessarily forced upon the population, but rather accepted by the society as a part of their cultural heritage. The ranking of 64 is slightly lower than the Asian average of $71^{16}$.

As an appropriate example, a teacher holds Phu Yai status over a student (Phu Noi) ${ }^{16}$. This results in an unwritten rule that teachers are simply correct and should not be questioned. Therefore, students who do not take the initiative are not generally expected to question points made in class lectures. In keeping with other norms in Thai society, classroom dynamics do not foster active, individual student response to presented material. The students would not think of interrupting the professor even if they do not understand the material.

Other examples of Phu Yai / Phu Noi status would include adults over children, bosses over employees, elder classmates over younger classmates, elder siblings over younger siblings, and even Thai over non-Thai. As a visitor to Thailand one may be assigned Phu Yai status as a sign of courtesy, stemming somewhat from assumptions regarding your wealth and education.

It was very common upon being introduced to a faculty member to quickly establish the Phu Yai status by verbally stating or questioning which degrees you had obtained from which university. This then establishes a hierarchy between the individuals involved in the greeting.

There is no doubt that educators from North America, particularly large urban environments would feel a sense of calm security in the environs of a Thai university. The ritual removing of footwear indicates an interesting informal atmosphere in a formal society. However, if as a guest or westerner, you did not follow suit it is unlikely you would be made aware of this. However the age old adage of "When in Rome..." applies here.

Perhaps, however, the most striking difference is purely visual. The students' attire is usually uniform. While this certainly has a pragmatic financial benefit, it also is indicative of uniformity or indeed cultural conformity. This is in stark contrast to the need for individual expression of western students. Hofstede states ${ }^{16}$.

Thailand's lowest Dimension is Individualism (IDV) at 20. A low score, as Thailand has, indicates the society is Collectivist as compared to Individualist. This is manifest in a close long-term commitment to the member 'group', is that a family, extended family, or extended relationships. Loyalty in a collectivist culture is paramount, and over-rides most other societal rules and regulations. The society fosters strong relationships where everyone takes responsibility for fellow members of their group.

Armed with the knowledge of Sanuk, Saving Face, Phu Yai, and a collectivist mentality one can better understand the group dynamic in the educational experience. 
Rajamangala University of Technology Thanyaburi (RMUTT).

The first example of the Phu Yai /Phu Noi status model we encountered was a third year architectural class at Rajamangala University of Technology Thanyaburi (RMUTT). If one takes into account the differences in culture previously noted, then this class at first glance is familiar to those of us who have attended and/or taught architecture. Chairs, students, a professor, and two site models prepared by two teams of students set the stage. We observed two teams presenting their proposals to affect a transitional area between the University Campus and the adjoining town. In a class of approximately 40 students, perhaps a maximum of six students were vocal in describing their proposals and methodologies.

There is little doubt that the inclusion of seven "farangs" or westerners into the established mix of an architectural class somewhat skews the standard group dynamic and one must factor that into account. To truly experience this as an everyday event it would be necessary to continually attend the classes until you were part of the everyday fabric of the process.

The professor informs us this is the norm for Thai students, few are vocal. In North America this is usually a sign of indifference or lack of attention; however in Thailand it appears to be indicative of the Phu Yai /Phu Noi relationship.

Mahasarakham University (MSU)

While our attendance at RMUTT was more as invited guest, our role at MSU was that of involved participant. Shortly after our arrival we participated in a group selection process where the visiting group of five students and three faculty were merged with Thai students and faculty into three main groups consisting of five members who would eventually develop different prototypes of possible bamboo products that could be manufactured by a local nearby village.

This was really a well thought out and informal warm up exercise which consisted of each student introducing themselves and then randomly selecting a name tag from a bamboo frame to hand off the next introduction. The group then headed off to the local village where, besides a walking tour of the village, the group participated in group bonding exercises of a traditional Thai lunch together and even planting rice much to the amusement of the local villagers.

In addition to being an eye opening experience for the westerners in attendance, it was also an excellent informal ice breaker while we strived to overcome the newness of the situation in addition to the language and cultural differences.

Over the course of the next week, we proceeded to work in both small groups and as a whole group that got together for presentations, meals, and informal get-togethers. As well, a further trip back to the village was necessary to cut actual bamboo to fabricate the prototypes the students had developed.

As the groups worked together over time [a day or two]the Thai students felt more comfortable with their varying abilities in English and the US students increased their use of Thai in 
accordance. The benefit to this experience was the subject matter itself, design. Design and architecture is a vocabulary of drawings, sketches, and models that formulates a universal language in the design field. This allowed the students to easily communicate visually and not have to rely on other communication methods which may provide a barrier to exchanging their ideas. This, in turn, helped the students broach other barriers of shyness and language in a way that those without the benefit of visual aids would not be able to do.

Removing students from their comfort zone or a familiar environment and immersing them in a culture where language or the written text is foreign to them forces them to rely on their other senses. This forces them to be more attentive to visual communication and will lead to a greater absorption of the learning process. This is in contrast to one of the least effective teaching techniques, that of a lecture ${ }^{17}$.

By far, the highlight of my experience in Thailand from both an educational and cultural experience was the string tying ceremony which is formally known as the Wai Kru. Literally Wai Kru means "Pay respect to the teacher" and is always performed on a Thursday which in Thailand is "Teachers Day."

This ceremony took place in a breezeway on the ground floor of the architectural building. This area is sheltered from the sun and rain but allows cooling breezes to flow through it. While this space was always occupied in one form or another during our stay, it was during this Wai Kru ceremony that it was lavishly decorated and completely full of students, faculty, musicians, and monks attending the ceremony.

It was interesting to attend a ceremony for the first time as it was impossible to know what to expect. What elements constituted the ceremony? How long an event would this be? What are the roles of the various participants? What are the meanings of the various parts?

The entire event is a serious treat for the senses. Large groupings of colorful flowers, hundreds of students in their matching uniforms, the bright orange robes of the row of monks off to the side, the pervasive hint of incense throughout, and the periodic music and chanting of the students create an otherworldly atmosphere that for first time western eyes leaves an indelible image. The first half of the ceremony is largely religious in nature, while the second half focuses on the secular. A constant parade of students approaches the professors, on their knees as a sign of reverence. Upon arrival, the professor, using their finger dipped in a small bowl of white paste, draws a small symbol on the forehead of the student and utters a short blessing of good fortune. As visiting faculty, Dr. Jan Cowan and I were included in parts of the ceremony. First we were blessed by the Dean of Architecture who then tied a white string, symbolizing purity, around our right wrist. The white thread is symbolic of "peace, harmony, good fortune and good health" we were told. We were also instructed to leave the string on for a minimum of three days before we removed it by untying it not by cutting it.

I personally chose to leave mine on until I returned home a month later.

Dr. Cowan and I were also graciously included in the prayers and singing of the students to the professors in attendance after which we were given gifts of flowers and incense. The fact that our 
hosts would include us in such a formal and significant part of their educational process was truly a great honor and indicative of the hospitality and respect of the Thai people.

In the myriad of sensory overload that was the Wai Kru ceremony, one aspect stood out above all others in its significance to architecture. In the succession of stages the students went through that day, one of the last required two students to kneel at a small low desk in front of a professor. On the desk was a small chalkboard upon which the professor had sketched a design with chalk. One student then placed his hand on top of the professor's hand, while the second student placed his hand upon the other two. The professor then traced the design he had drawn earlier which in turn caused the students' hands to follow or mimic his sketch. This ritual symbolizes the transfer of knowledge from the Phu Yai to the Phu Noi and is emblematic of the educational process itself. A simple, concise, and visual representation of architectural education.

\section{Reflective Comments from a Student Perspective}

This part of the discussion focuses upon the Thai teacher/student interrelationship and how this varies and compares to what one of our students (at the graduate level) has experienced in the United States. The following is his contribution to this dialogue and is spoken in his words, supported by his scholarly research into the topic:

The goals herein were to describe and discuss what I saw/heard/tasted from a student's perspective with respect to the following two specific scenarios:

1. The architectural class we observed at Rajamangala University of Technology Thanyaburi (RMUTT).

2. The Professor Appreciation/String Tying Ceremony at Mahasarakham University (MU).

According to Bodhi ${ }^{18}$ (1997), education is the main tool of human growth; education literally means "to bring forth," which shows that the most important task of this process is to draw forth from the mind its innate capacity for understanding. Bodhi stated that the Buddhist principles aim is to promote values of education in order to increase knowledge. Conversely, in comparison to formal education today, in the United States, the Thai classroom organization had a greater impact on student conduct and academic results. In the United States, by contrast, classroom instruction has become routine, and students often consider school a mandatory long term path to overcome life's obstacles rather than motivation for learning and an opportunity to gain knowledge. In the West, teachers often face a dilemma with the educational system that they find difficult to control, monitor, and maintain.

I really enjoyed the experience of being abroad and visiting Thailand, a wonderful country. In Thailand, the teacher is perceived as a venerable person who has to uphold high standards of conduct $^{19}$. The Thai teacher/student interrelationship is very special, and it will be discussed using the class instruction and teaching framework seen at RMUTT and by describing the most important Thai school event, the Wai Kru ceremony ritual, that I was fortunate to experience at MSU. During the Wai Kru ceremony, Thai students demonstrate how much they value their teachers' dedication to passing on knowledge to them. 


\section{The Architectural Class Experience at RMUTT}

While much has been written about the architectural teaching methodology and architecture students' attitudes in Thailand, I'd like to write about my experiences of the active promotion of collaborative learning from my study abroad trip to Thailand. My role was that of a visiting student observer and critic in RMUTT's Urban Design Studio that featured start up model projects designed by 4th-year students majoring in Urban Planning and Design.

The first thing that impressed me was the Thai students' politeness while entering the classroom. There was a traditional practice of the students taking off their shoes before entering the classroom. Before the start of class, Thai students show politeness by greeting the teacher with the word "Sawatdi khrap" for male students or "Sawatdi kha" for female students while raising the pressed palms until the thumbs touch the tip of the nose and the fingertips touch the space between the eyebrows. I also noticed that the students are very polite and greet one another at all times of the day. Between them, the word 'Sawatdi' alone is sufficient for greeting.

According to Kiengsiri, Bhinyoying, \& Promathatavedi ${ }^{20}$, the Thai school system uses Thai Social Etiquette principles published by the Royal Thai Ministry of Culture which teaches the official version of 'good manners.' This manual is intended to inform foreign visitors on Thai codes of social behaviors based on Thai culture, customs, community engagement, and Buddhism.

The same source states that there are three basic levels of greeting gestures, also called "wai," associated with the word "Sawatdi khrap" or "Sawatdi kha" if they are male or female. A "wai" is a sign of pressing the palms together in the position of a budding lotus at chest level, with the fingertips touching the tip of the nose. Students always use the second level "wai" to greet their teacher when they see them, and then the teacher responds with the same gestures and greeting. Therefore, Thai students and teachers develop mutual respect for one another.

Another situation that caught my attention about the teaching environment compared with my own was the general attitude around the university and the students' community engagement skills. I noticed that Thai students were more serious, disciplined, and better behaved than their counterparts in the United States. I was surprised how one teacher could control an architecture studio of 40 students who were quiet and diligent during the lecture sessions.

As I observed the classroom situation, I noticed that the class sizes were large compared to class sizes in the United States. Conducting a studio that revolves around 30-40 students with only four or five students who are really involved can be challenging. According to Barrow ${ }^{21}$, the traditional method of teaching in Thailand has been the rote method which works well when the class size is large. The teacher is better able to maintain discipline when all the students are doing the same thing at the same time. Therefore, it is very important to decrease student numbers per group. In this case, in order to optimize the class results, the teacher worked concurrently with two groups of about 20 students instead of with one group consisting of 40 people. There were a significant number of very bright Thai students in the class.

However, based on the students' shy and modest behavior and the teacher's tolerance of this behavior, which are features of Thai culture and the Buddhist religion, it was not easy to identify 
the level of the students' talents. The respectful behavior of Thai students did not allow them to look the teacher in the eye when responding. To ask questions or to talk during the lecture, each student was expected to raise a finger. The more students that were lifting a finger, the more the class was considered proactive, and the more they assimilated the lesson topic and knowledge. A disadvantage of this method of teaching, however, is that students are taught what to think instead of how to think ${ }^{21}$.

The Thai professor' demeanor was very friendly, patient, and helpful, but I had the impression that he had developed a special way to convey his teaching material, and to retrieve information from students. During the class session, the teacher conducted his course using jokes and idioms to convey the class material. This method worked better than actually trying to teach using conventional methods. The teacher said that he tries to get them to talk and that he likes to make his classes fun. As Marzano and Pickering ${ }^{22}$ state, "The quality of teacher-student relationships is the keystone for all other aspects of classroom management". In fact, this observation was confirmed later when I noticed that Thai teaching methods are based on Thai culture and Buddhism.

Prior to starting the lecture, the teacher asked students to form two groups conforming to the number of projects to be presented. The classes were composed of approximately 40 students who were well behaved during the class session. Each group had to present its project model. The technique used by the teacher was to initiate a class discussion, and then each group was charged with commenting and criticizing the other group projects.

The objective of the lesson was to discuss the conceptual urban planning sketch model of the extension project of the RMUTT University Campus. The Urban Design professor in charge of the studio demonstrated experiential learning strategies based on applied pedagogy (teaching methodology) and community engagement to provide a better school living environment for students. These strategies included using knowledge to solve problems, to conduct analyses, and to understand the relevance of information to situations encountered such as: (1) the way to access the site, (2) a description of each project concept and the characteristics of each approach using existing urban planning data collected from photographs and topographical maps, (3) determination of significant changes and potential impact that will occur in students' behaviors and perceptions of the project under a cultural (non-academic factors) and educational paradigm using oral tradition and empirical learning system based essentially on verbal, visual and listening factors and a modern artistic design methodology concept, and (4) investigation using comparative different factors, such as motivation, group exchange, learning and communication through teamwork. According to Johnson, Johnson and Smith ${ }^{23}$, such active learning strategies are increasingly recommended as the alternative[to non-active styles], in which students are empowered to think and learn for themselves.

Once the lesson has started, the teacher used tips to conduct the lesson in a manner to increase students' participation level because to obtain better lesson outcomes in the architecture and design learning environment it is fundamental that each educator teaches according to his/her own set of ideologies and beliefs and in a manner that is distinct from others ${ }^{24}$

Thai students are shy in general and only a small number of students routinely answer questions. When I spoke with the architecture professor about this, he responded that this is how things are in Thailand. The causes of the Thai students' lack of participation is authentic and natural 
classroom settings have been explored. Among several reasons for this occurrence, one that has gained attention is the important role of the teacher in the Thai education system. According to Reeve, Bolt \& $\mathrm{Cai}^{25}$, a significant role is played by teachers in inspiring and motivating students to learn, and for creating opportunities that enhance the motivation of the learners. It is important for teachers to discover "what motivates their students."

The Thai students presented two projects during the class. Each project proposed the solution for integrating the campus with its surrounding vicinities using pedestrians' bridge connections, improving the water quality of the existing canal, and planning to create a green park along the canal. Each group presented its concept under two different views, each one defending a specific aspect of the project:

- Prioritization of the architecture and the mass (scale) of the new building within the campus boundaries

- Placing the emphasis on the existing urban factors, existing streets and building located by the project site, respecting the existing building scale within the neighborhood.

The professor proceeded by questioning each group to explain the concept and the process of each project, and by assisting each group by asking thorough and well-focused questions to transform their knowledge into the technical skills required to perform a task.

In conclusion, culture and education are interdependent multidimensional issues which carry a cause and effect that can impact one another. Thai culture and the Buddhist religion appear to have a strong impact on the educational system and Thai teacher/student interrelationships. According to Durrant, Brown, Cluff, \& Bevell ${ }^{26}$, in South East Asia it takes a combination of academic rigor, the right opportunities for student involvement, a combination of high expectations and high faculty support, and the right motivations and expectations to produce an international program that will truly impact students academically, socially, and culturally. Nevertheless, based on my personal experience in Thailand, I have noticed some discrepancies to be addressed between American teacher/student interrelationships and Thai teacher/student interrelationships. As a recommendation to American teachers and students to perform well in the Thai educational system, any foreign teachers and students should be committed to learn as much about Thai culture and tradition and Thai Buddhism[as they can]. They should also avoid controversial behaviors that might not be understood by Thai teachers and students and that might cause embarrassment.

Mahasarakham University 2010 Wai Kru Ceremony-Teacher Appreciation Day

The Wai-Kru experience at the Faculty of Architecture of Mahassarakam University taught me some important aspects of teaching art in Thailand. The educational system of Thai architecture and design emphasizes the philosophy of "Learning by Doing" which is strongly tied with Thai culture $^{28}$. In many cultures, a teacher's responsibility was, first and foremost, to assist young people to grow into the type of persons that would be valued by the community.

The Wai Kru ceremony showed how important students value the work of the faculty and staff at the school and, in return, the teachers promise to do their best to help each and every student achieve their full potential. Students promise to study seriously and patiently, respect the 
teachers, behave fairly to their fellow students, and use the knowledge gained properly, and so on.

Although teachers are recognized as being respected within all cultures, the Wai Kru ceremony performed by Thai students truly demonstrates the esteem in which teachers are held. The respect students have for their Ajarns, or teachers, is apparent and obvious, respect which is graciously accepted by the Ajarns.

In summary, as a foreign student coming from western society, I was amazed by this kind of ceremony which seemed very strange to me. I initially had the feeling that Thai students are alienated from their ancient tradition and culture. However, it did not take long to realize that I was misjudging them. I was quickly impressed by the discipline and attitude of all these students ready to witness their commitment to their teachers, according to the Buddhist tradition, culture, and doctrine within a tangible atmosphere full of joy and happiness. This was reciprocated in their tacit acceptance of the student blessings and good wishes by the faculty. The Dean and instructors of the faculty gave speeches to the students offering advice on learning with an emphasis on thinking and doing good things for the community and the country. I was also impressed by the teachers' willingness to share their knowledge with students. According to Avalos Beatrice \& Haddad Wadi ${ }^{27}$, instruction, personal guidance, and exemplary behavior are important elements of a teacher's role.

The Michigan Department of Education and Linda Smith in her MI-Map Packet published a document called Strengthening Teacher-Student Relationships - Tending to the Spirit/Culture in which Alice Terry, author of More Life through Management stated "A fundamental question for a student is 'Does my teacher like me?' Given a rigorous, aligned curriculum, the answer to that simple question is our best predictor of student achievement." ${ }^{28}$ Although some Thai teachers emphasize a rigorous curriculum, many students finish their class with great achievements because of the teachers' patience, compassion, and readiness to assist them in obtaining knowledge.

According to Richard Barrow on http://www.thaischolllife.com, Thai schools are fairly similar to other schools around the world. However, there are some interesting differences that can be attributed to the uniqueness of Thai culture. The differences can range from simple things, such as shoes not being allowed to be worn in the school buildings, to the Wai Kru ceremony which is performed annually, and to students showing reverence and respect towards their teachers in a very public manner.

\section{Summary and Implications for Future Research}

As educators and practitioners of architecture, particularly in foreign settings, it is common to become immersed in the new and culturally rich physical environment and miss the subtleties of the educational environment and the lessons that can be gained in watching the interplay between students and teachers. How often do we, as western educators, take the time to state how we appreciate our students and the opportunity to teach them? How often do we take the time to fully listen to them? 
The value of this paper is intended to be in the narratives provided above by each participant. However, in reviewing these narratives, the lessons may need to be emphasized again so they are not missed. For example, the comments from our Thai host come steeped in Thai educational history and indicate a foundation of tradition and ceremony that is certainly lacking in the architectural schools in North America. We see through him that these ceremonies and interchanges with students are set within the first few days of classes and are also reinforced by ethical and moral codes set by the federal government. This tends to bring some consistency into the Thai teacher-student interrelationship. Having noted this, though, one can sense that the freedoms within American education are seen by the Thai professor as an impetus to creative architectural thought that is not encumbered by cultural tradition.

It should be pointed out that each contributor to this paper was not aware of the others' statements while they composed their own story of the events. Therefore it is interesting to note that our student's comments (with respect to what he saw and heard) reflect what the Thai instructor says his students are instructed to do. All of the politeness and good manners witnessed are part of the moral education that he speaks of and that infuse architectural education in Thailand. However, the class we observed at RMUTT also indicates that this particular teacher used fairly contemporary techniques and the students, though shy, participated. So perhaps, as noted by the Thai professor, the Thai teaching protocol is changing with the next generation of teachers. It certainly appeared that the majority of the Thai students really enjoyed this type of instruction, even though only a few were active participants as they were called out to speak. As well, it is enlightening to see that the student noticed that elements of mutual respect, which were emphasized in the Wai-Kru ceremony, were carried into a classroom of over 40 students and led to the ordered delivery of the instructional material.

This type of dialogue opens up the possibility of exploring some of the work of Alice Terry who, as noted above, examines the importance of student engagement and its relationship to student achievement. Do these experiences (e.g., Wai-Kru) help students feel that their teachers like them and does feeling this motivate students to be more engaged? Should this kind of relationship be nurtured and supported within design education, as this author suggests? Do Thai and American students who are high achievers feel that their teachers like them? Is this a line of research worth examining further? Obviously, this type of discussion expands potential research questions that could be explored and also add a cultural dimension to Terry's work and hypothesis.

It is also interesting to note that the comments made by the Canadian instructor, particularly those that he cited, echo and reinforce the comments of the Thai professor. The Canadian instructor also points out how the critique session format is similar to that in North America. Both his comments and the student's emphasize the sensory richness of the Wai-Kru ceremony. Of the many sites and events that were seen in Thailand, this certainly layered many elements of their culture into an amazing sequence of teachable events.

So what does this mean for architectural education? What has been learned through this discussion that could be turned into best practices? 
Perhaps several lessons come to the forefront that we can bring to our discipline of design and therefore become the lessons we often miss while being enthralled by the new architectural wonders in the foreign lands we visit:

1. Develop mutual respect of opinion and others within our educational environments.

2. Embrace the culture one is visiting without denouncing the culture one is from.

3. Build in reflection opportunities at numerous junctures to help learning take place.

4. Build in (if possible) opportunities for the visitors to authentically share best practices from own culture so those being visited can learn.

5. Instill in students the value of learning.

6. Make better and more frequent use of our seasoned practitioners to come and teach, keeping in mind that practitioners need not always be architects and engineers, but perhaps those that can provide alternative viewpoints to the complex problems of design.

7. Make design education more than just a visual education or a slide show of great architectural engineering. Steep students in the music, food, and religion of a country (or region of a country) if they are going to design in that context.

8. Incorporate a sense of fun (Sanuk) into how we teach and how students learn.

9. Stress a sense of collectivity over individual merit. This would be especially worthwhile in the many team projects that design students become engaged in in school and in their professional lives.

10. Spend more time concentrating on the development of the individual versus spending time on the development of the particular design only. As noted by our student we need to "assist young people to grow into the type of persons that would be valued by the community."

11. Explore the use of common visual, graphic language (sketching) in the arts and how this becomes the common language between different cultures.

12. Ensure that our students understand the correct codes of professional behavior in the design world. These types of behavior need to be encouraged/enforced in the classroom as well.

13. Enforce the importance that poorly conceived design can be dangerous to the community and that the skills that we are teaching should be used for promoting the greater good of a designed world.

14. Ensure that teachers realize the importance of determining what motivates their students.

Yet one should be cautious as we move forward into this field of cross-cultural teaching and learning. Perhaps our student's comments sum up part of the difficulty in drawing too many definitive conclusions from this: "In conclusion, culture and education are interdependent multidimensional issues which carry a cause and effect that can impact one another." Based on this alone, this becomes a ripe area for research when looking at improving the current state of American design education.

\section{Bibliographic Information}

1. Study Abroad Stats: VistaWide World Languages and Cultures: Retrieved from: http://www.vistawide.com/studyabroad/study_abroad_statistics.htm. 
2. Engel, 1., Engel, J. (2011, Jan 11).Assessing Language Acquisition and Intercultural Sensitivity Development in Relation to Study Abroad Program Design. Retrieved from: http://www.frontiersjournal.com/issues/vol10/vol10-13_EngleEngle.pdf

3. Cornell University. Retrieved from: http://aap.cornell.edu/arch/news/newsitem.cfm?customel_datapageid_2892=443045

4. Crisman, P. (2007). Working on the Elizabeth River. Journal of Architectural Education, 61, 84-91.

5. Young-Puh, R. G. (2005). Architectural practice and education in South Africa: From local transformation to global participation. Journal of Architectural Education, 58, 33-42. doi: 10.1162/1046488053420898

6. Bing, J. (2001). Ideas and realities: Rebuilding in postwar Mostar. Journal of Architectural Education, 54, $238-249$.

7. Mazumdar, S. (1993). Cultural values in architectural education: An example from India. Journal of Architectural Education, 46 (4), 230-238.

8. Brady, D.A. (1996).The education of an architect: Continuity and change. Journal of Architectural Education, 50 (1), 32-49.

9. Poole, D. (2001).Moving towards professionalism: The strategic management of international education activities at Australian Universities and their faculties of business. Higher Education, 42 (4), 395-435 .

10. Desimone, L., Smith, T., Baker, D., Ueno, K. (2005). Assessing barriers to the reform of U.S. mathematics instruction from an international perspective. American Educational Research Journal,42 (3), 501-535.

11. Abrandt- Dahlgren, A., Larsson, S., Walters, S. (2006). Making the invisible visible. On participation and communication in a global, web-based master's programme. Higher Education, 52 (1),69-93 .

12. Dolby, N., Rahman, A. (2008). Research in international education Review of Educational Research, 78 (3), 676-726.

13. Tadanao, E., Edwards, E. (1995). Early buddhist temples in Japan: Roof-Tile manufacture and the social basis of temple construction. World Archaeology, 27 (2), 336-353.

14. Colless, B. (1970). Divine Education. Numen, 17 (2), 118-142.

15. National Identity Board (2005). Thailand: Traits and Treasures. Office of The Permanent Secretary, The Prime Minister's Office. Retrieved from http://studyinthailand.org/Thai_culture/sanuk.html.

16. Hofstede, G. Cultural Dimensions. Retrieved from http://www.geert-hofstede.com/hofstede_thailand.shtml

17. Broadwell, M. Lecture Method of Instruction. (Instructional Design Library 27). Available from http://www.fetchbook.info/compare.do?search=9780877781479

18. Bodhi, B. (1997). Aims of Buddhist Education. Access to Insight, 35. Retrieved from http://www.accesstoinsight.org/lib/authors/bodhi/bps-essay_35.html

19. Suvannathat, C. (1978) Study of remote area teachers' attitudes toward children. Paper submitted to the Seminar on Mental Health, Organized by Division of Mental Health, Ministry of Health, February 13-18. 
20. Kiengsiri, P., Bhinyoying, S., \&Promathatavedi, M. (2007). In K. M. Chavalit (Ed.). Thai Social Etiquette, (Chapter 3). Bangkok, Thailand: Ministry of Culture.

21. Barrow, P. (2010). Respect for Thai teachers ceremony. Retrieved from http://www.thaiblogs.com/2010/06/03/respect-for-thai-teachers-ceremony-2/

22. Marzano, R. J., Pickering, J., et al. (1997). Dimensions of learning teacher's manual (2nd ed.). Aurora, Colorado: McREL.

23. Johnson, D. W., Johnson, R. T., \& Smith, K. A. (1991). Cooperative Learning: Increasing college faculty instructional productivity. ASHE-FRIC Higher Education Report No.4. Washington, D.C.: School of Education and Human Development, George Washington University.

24. Salama, A. (2006). Design studio teaching practices: Between traditional, revolutionary, and virtual models. Retrieved from http://www.openhouse-int.com/

25. Reeve, J., Bolt, E., \& Cai, Y. (1999). Autonomy-supportive teachers: How they teach and motivate students. Journal of Educational Psychology, 91, 537-548.

26. Durrant, M.B., Brown, R.B., Cluff, J.B., \& Bevell, J.W. (n.d.). Mentored service learning and rigorous academics: Keys to successful international study abroad programs. Retrieved from: http://www.mesacc.edu/other/engagement/Journal/Issue8/Durrant.pdf

27. Avalos, B., \& Haddad, W. (1981). A review of teacher effectiveness research in Africa, India, Latin America, Middle East, Malaysia, Philippines, and Thailand: Synthesis of results. Ottawa, Ont., CA, IDRCTS23e, 1981, 128.

28. Smith, L. (n.d.). Strengthening teacher-student relationships - Tending to the spirit/culture. MI-Map, Michigan Journal of Education. 


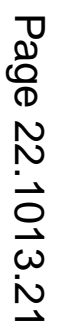

